\title{
A New Tool for QSPR Researches: ev-degree Randić Index
}

\author{
Süleyman Ediz* \\ Faculty of Education, Yüzüncü Yıl University, Van, Turkey, \\ suleymanediz@yyu.edu.tr \\ *Corresponding author
}

Received: 29 December 2016

Accepted: 22 May 2017

DOI: $10.18466 /$ cbayarfbe.339313

\begin{abstract}
Topological indices have important role in theoretical chemistry for QSPR researches. Among the all topological indices the Randić index has been used more considerably than any other topological indices in chemical and mathematical literature. Most of the topological indices as in the Randic index are based on the degrees of the vertices of a connected graph. Recently novel two degree concepts have been defined in graph theory; ev-degrees and ve-degrees. In this study ev-degree Randić index is defined by using ev-degree concept as parallel to their corresponding classical degree version. This new ev-degree Randić index is compared with the Randić index by modelling some physicochemical properties of octane isomers. It is showed that the evdegree Randić index give better correlation than the Randić index to predict the entropy, acentric factor and standard enthalpy of vaporization of octanes. Also the exact values of the ev-degree Randic index for the well-known graph classes such as; paths, cycles, stars and complete graphs are given.
\end{abstract}

Key Words: ev-degree Randić index, octane isomers, QSPR studies, Randić index, topological indices

\section{Introduction}

Graph theory which is an important branch of applied mathematics has many applications to modelling real world problems from science to technology. Chemical graph theory which is a fascinating branch of graph theory has many applications related to chemistry. Chemical graph theory provides many information about molecules and atoms by using pictorial representation (chemical graph) of these chemical compounds. A topological index which is a numerical quantity derived from the chemical graph of a molecule is used to modelling chemical and physical properties of molecules in QSPR/QSAR researches. Quantitative structure-property/activity relationships (QSPR/QSAR) studies have very important role in theoretical chemistry. Octane isomers have been used widely in QSPR studies. The role of octane isomers in QSPR studies, we refer the interested reader [1-4] and references therein. Among the all topological indices, the Randić index is the most used topological index in the chemical and mathematical literature so far. Very recently, Chellali, Haynes, Hedetniemi and Lewis have published a seminal study: On ve-degrees and ev-degrees in graphs [5]. The authors defined two novel degree concepts in graph theory; ev-degrees and ve-degrees and investigate some basic mathematical properties of both novel graph invariants with regard to graph regularity and irregularity [5]. After given the equality of the total ev-degree and total ve-degree for any graph, also the total ev- degree and the total ve-degree were stated as in relation to the first Zagreb index. It was proposed in the article that the chemical applicability of the total ev-degree (and the total ve-degree) could be an interesting problem in view of chemistry and chemical graph theory.

In this study we define ev-degree Randić index by using the ev-degree concept. We define this novel topological index as parallel to corresponding original definitions of based on classical degree concept. We compare this new ev-degree Randić index with the Randić index by modelling some physicochemical properties of octane isomers.

\section{Preliminaries}

In this section we give some basic and preliminary concepts which we shall use later. A graph $G=(V, E)$ consists of two nonempty sets $V$ and 2-element subsets of $V$ namely $E$. The elements of $V$ are called vertices and the elements of $E$ are called edges. For a vertex $v, \operatorname{deg}(v)$ show the number of edges that incident to $v$. The set of all vertices which adjacent to $v$ is called the open neighborhood of $v$ and denoted by $N(v)$. If we add the vertex $v$ to $N(v)$, then we get the closed neighborhood of $v, N[v]$.

Randic investigated the measuring the extent of branching of the carbon-atom skeleton of saturated hydrocarbons via Randić index [6]. The Randić index of a connected graph 
$G$ defined as;

$$
R=R(G)=\sum_{u v \in E(G)}(\operatorname{deg}(u) \cdot \operatorname{deg}(v))^{-1 / 2}
$$

We refer the interested reader to [7-9] and the references therein for the up to date arguments about the Randić index.

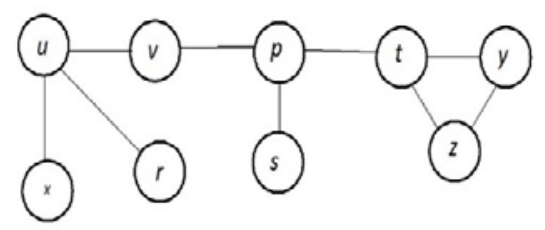

Figure 1 The graph $G$ for the Example 2.3

And now we give the definitions of ev-degree and ve-degree concepts which were given by Chellali et al. in [5].

Definition 2.1 [5] Let $G$ be a connected graph and $v \in$ $V(G)$. The ve-degree of the vertex $v, \operatorname{deg}_{v e}(v)$, equals the number of different edges that incident to any vertex from the closed neighborhood of $v$. For convenience we prefer to show the ve-degree of the vertex $v, c_{v}$.

Definition 2.2 [5] Let $G$ be a connected graph and $e=$ $u v \in E(G)$. The $e v$-degree of the edge $e, \operatorname{deg}_{e v}(e)$, equals the number of vertices of the union of the closed neighborhoods of $u$ and $v$. For convenience we prefer to show the $e v$-degree of the edge $e=u v, c_{e}$ or $c_{u v}$.

We illustrate these new degree definitions for the vertices and edges of the graph $G$ which are shown in Figure 1 .

Example 2.3 Notice that for the vertices of $G$, we get $c_{x}=$ $3, c_{u}=4, c_{v}=6, c_{r}=3, c_{p}=6, c_{s}=3, c_{t}=6, c_{z}=4$ and $c_{y}=4$. And for the edges of $G$, we get $c_{x u}=4, c_{u v}=$ $5, c_{u r}=4, c_{v p}=5, c_{p t}=6, c_{p s}=4, c_{t z}=4, c_{t y}=4$ and $c_{y z}=3$.

Definition 2.4 [5] Let $G$ be a connected graph and $v \in$ $V(G)$. The total $e v$-degree of the graph $G$ is defined as;

$$
T_{e}=T_{e}(G)=\sum_{e \in E(G)} c_{e}
$$

And the total ve-degree of the graph $G$ is defined as;

$$
T_{v}=T_{v}(G)=\sum_{v \in V(G)} C_{v}
$$

Observation 2.5 [5] For any connected graph G,

$$
T_{e}(G)=T_{v}(G)
$$

The following theorem states the relationship between the first Zagreb index and the total ve-degree of a connected graph $G$.

Theorem 2.6 [5] For any connected graph G,

$$
T_{e}(G)=T_{v}(G)=M_{1}(G)-3 n(G)
$$
where $n(G)$ denotes the total number of triangles in $\mathrm{G}$.

We can restate the Theorem 2.1 for the trees which are acyclic and are not contain any triangles.

Corollary 2.7 For any tree $T$,

$$
T_{e}(T)=T_{v}(T)=M_{1}(T)
$$

And from this last equality we naturally consider to apply this novel ev-degree concept to chemical graph theory by introducing ev-degree Randić index.

Definition 2.8 Let $G$ be a connected graph and $e \in E(G)$. The ev-degree Randic index of the graph $G$ is defined as;

$$
R^{\beta}=R^{\beta}(G)=\sum_{e \in E(G)} c_{e}^{-1 / 2}
$$

\section{Results and Discussions}

In this section we compare the $e v$-degree Randic index with the well-known the classical Randic index by using strong correlation coefficients acquired from the chemical graphs of octane isomers. We get the experimental results at the www.moleculardescriptors.eu (see Table 1).

The following physicochemical features have been modeled:

- Entropy (E),

- Acentric factor (A),

- Enthalpy of vaporization (H),

- Standard enthalpy of vaporization (D).

We select those physicochemical properties of octane isomers for which give reasonably good correlations, i.e. the coefficients are larger than 0.9 (see Table 2).

Note that the all values in Table 2 are given by using natural logarithm. It can be seen from the Table 2 that the most convenient indices which are modelling the Entropy, Enthalpy of vaporization (HVAP), Standard enthalpy of vaporization (DHVAP) and Acentric factor (AcenFac) are ev-degree Randić index for entropy, acentric factor and the standart enthalpy of vaporization (DHVAP) and Randić index for the enthalpy of vaporization (HVAP), respectively. Also it can be shown from the Table 4 that the correlation efficient between the indices is 0.9901 which is indicate strong correlation. From the above arguments, we can say that the vedegree Randić index is a better possible tools for QSPR researches than the Randić index.

Table 1. Some physicochemical properties of octane isomers.

\begin{tabular}{|l|c|c|c|c|}
\hline Molecule & E & A & H & D \\
\hline n-octane & 111.70 & 0.39790 & 73.19 & 9.915 \\
\hline 2-methyl-heptane & 109.80 & 0.37792 & 70.30 & 9.484 \\
\hline 3-methyl-heptane & 111.30 & 0.37100 & 71.30 & 9.521 \\
\hline
\end{tabular}


Celal Bayar University Journal of Science

Volume 13, Issue 3, p 615-618

S. Ediz

\begin{tabular}{|l|l|l|l|l|}
\hline 4-methyl-heptane & 109.30 & 0.37150 & 70.91 & 9.483 \\
\hline 3-ethyl-hexane & 109.40 & 0.36247 & 71.70 & 9.476 \\
\hline 2,2-dimethyl-hexane & 103.40 & 0.33943 & 67.70 & 8.915 \\
\hline 2,3-dimethyl-hexane & 108.00 & 0.34825 & 70.20 & 9.272 \\
\hline 2,4-dimethyl-hexane & 107.00 & 0.34422 & 68.50 & $9, .029$ \\
\hline 2,5-dimethyl-hexane & 105.70 & 0.35683 & 68.60 & 9.051 \\
\hline 3,3-dimethyl-hexane & 104.70 & 0.32260 & 68.50 & 8.973 \\
\hline 3,4-dimethyl-hexane & 106.60 & 0.34035 & 70.20 & 9.316 \\
\hline $\begin{array}{l}\text { 2-methyl-3-ethyl-pen- } \\
\text { tane }\end{array}$ & 106.10 & 0.33243 & 69.70 & 9.209 \\
\hline $\begin{array}{l}\text { 3-methyl-3-ethyl-pen- } \\
\text { tane }\end{array}$ & 101.50 & 0.30690 & 69.30 & 9.081 \\
\hline $\begin{array}{l}\text { 2,2,3-trimethyl-pen- } \\
\text { tane }\end{array}$ & 101.30 & 0.30082 & 67.30 & 8.826 \\
\hline $\begin{array}{l}\text { 2,2,4-trimethyl-pen- } \\
\text { tane }\end{array}$ & 104.10 & 0.30537 & 64.87 & 8.402 \\
\hline $\begin{array}{l}\text { 2,3,3-trimethyl-pen- } \\
\text { tane }\end{array}$ & 102.10 & 0.29318 & 68.10 & 8.897 \\
\hline $\begin{array}{l}\text { 2,3,4-trimethyl-pen- } \\
\text { tane }\end{array}$ & 102.40 & 0.31742 & 68.37 & 9.014 \\
\hline $\begin{array}{l}\text { 2,2,3,3-tetramethyl- } \\
\text { butane }\end{array}$ & 93.06 & 0.25529 & 66.20 & 8.410 \\
\hline
\end{tabular}

\begin{tabular}{|l|l|l|}
\hline 2,3,4-trimethyl-pentane & 3.553 & 3.316 \\
\hline 2,2,3,3-tetramethylbutane & 3.250 & 3.037 \\
\hline
\end{tabular}

Table 4. The cross correlation matrix of the ev-degree Randić and Randić indices.

\begin{tabular}{|c|c|c|}
\hline Index & $\mathrm{R}$ & $\mathrm{R}^{\beta}$ \\
\hline $\mathrm{R}$ & 1.0000 & \\
\hline $\mathrm{R}^{\beta}$ & 0.9901 & 1.0000 \\
\hline
\end{tabular}

Also we find the the Randic index of octane isomers values at the www.moleculardescriptors.eu (see Table 3). We also calculate and show the $e v$-degree Randić index of octane isomers values in Table 3.

4 ev-degree Randić index for general graph classes In this section we give the exact values of the $e v$-degree Randić index for the well-known graph classes such as; paths, cycles, stars and complete graphs.

Theorem 4.1 Let $P_{n}$ be a $n$-vertex path $n \geq 5$ vertices then;

$$
R^{\beta}\left(P_{n}\right)=\frac{n-3}{2}+\frac{2}{\sqrt{3}}
$$

Table 2. Correlation coeficients between Randić indices and sone physicochemical properties of octane isomers.

\begin{tabular}{|c|c|c|c|c|}
\hline Index & Entropy & AcenFac & HVAP & DHVAP \\
\hline $\mathrm{R}$ & 0.9063 & 0.9043 & 0.9359 & 0.9580 \\
\hline $\mathrm{R}^{\beta}$ & 0.9231 & 0.9299 & 0.9320 & 0.9613 \\
\hline
\end{tabular}

Table 3. Topological indices of octane isomers.

\begin{tabular}{|l|c|c|}
\hline Molecule & $\mathrm{R}$ & $\mathrm{R}^{\beta}$ \\
\hline n-octane & 3.914 & 3.655 \\
\hline 2-methyl-heptane & 3.770 & 3.525 \\
\hline 3-methyl-heptane & 3.808 & 3.549 \\
\hline 4-methyl-heptane & 3.808 & 3.549 \\
\hline 3-ethyl-hexane & 3.846 & 3.574 \\
\hline 2,2-dimethyl-hexane & 3.561 & 3.327 \\
\hline 2,3-dimethyl-hexane & 3.681 & 3.433 \\
\hline 2,4-dimethyl-hexane & 3.664 & 3.419 \\
\hline 2,5-dimethyl-hexane & 3.626 & 3.394 \\
\hline 3,3-dimethyl-hexane & 3.621 & 3.366 \\
\hline 3,4-dimethyl-hexane & 3.719 & 3.457 \\
\hline 2-methyl-3-ethyl-pentane & 3.719 & 3.457 \\
\hline 3-methyl-3-ethyl-pentane & 3.682 & 3.404 \\
\hline 2,2,3-trimethyl-pentane & 3.481 & 3.244 \\
\hline 2,2,4-trimethyl-pentane & 3.417 & 3.197 \\
\hline 2,3,3-trimethyl-pentane & 3.504 & 3.258 \\
\hline
\end{tabular}

Proof There are $n-3$ edges with their ev-degrees equal 4 and 2 edges with their ev-degrees equal 3 for the $n$-vertex path. From this,

$$
\begin{gathered}
R^{\beta}\left(P_{n}\right)=(n-3) * 4^{-1 / 2}+2 * 3^{-1 / 2} \\
=\frac{n-3}{2}+\frac{2}{\sqrt{3}}
\end{gathered}
$$

Theorem 4.2 Let $C_{n}$ be a n-vertex cycle $n \geq 4$ vertices then;

$$
R^{\beta}\left(C_{n}\right)=\frac{n}{2}
$$

Proof Note that every edge degree (ev-degree) is 4 for any cycle. From this, we can get,

$$
R^{\beta}\left(C_{n}\right)=n * 4^{-1 / 2}=\frac{n}{2}
$$

Theorem 4.3 Let $S_{n}$ be a $n$-vertex star $n \geq 3$ vertices then;

$$
R^{\beta}\left(S_{n}\right)=\frac{n-1}{\sqrt{n}}
$$

Proof Note that the $e v$-degrees of all edges of the star graph are $n$. There are $n-1$ edges for every star. From this fact we acquired the desired result.

Theorem 4.3 Let $K_{n}$ be a n-vertex complete graph $n \geq 4$ vertices then;

$$
R^{\beta}\left(K_{n}\right)=\frac{n(n-1)}{2 \sqrt{n}}
$$

Proof Note that the $e v$-degrees of all edges of the complete graph are $n$. There are $\frac{n(n-1)}{2}$ edges for every complete graph. From this fact we acquired the desired result. 


\section{Conclusion}

We proposed the novel ev-degree Randić index based on evdegree concept which has been defined very recently in graph theory. It has been shown that this index can be used as predictive means in QSAR researches. Predictive power of this index has been tested on by using some physicochemical properties of octanes. Acquired results show that the new ev-degree Randić index give somewhat better results by analogy well-known the Randić index. In addition, we investigated basic mathematical properties of these novel topological indices for general graph classes. It can be interesting to find a lower and upper bounds for the simple connected graphs. It can also be interesting to investigate the relations between the ev-degree Randić index and the other well-known topological indices such as; Zagreb, Wiener and Hosoya topological indices.

\section{References}

1. Kuanar, M.; Kuanar, S.K.; Mishra, B.K.; Gutman, I. Correlation of line graph parameters with physicochemical properties of octane isomers. Indian Journal of Chemistry-Section A. 1999; 38, 525-528.

2. Randić, M. Quantitative structure-property relationship. Boiling points of planar benzenoids. New Journal of Chemistry. 1996; 20,10011009.

3. Randić, M.; Pompe, M. On characterization of CC double bond in alkenes. SAR and QSAR in Environmental Research. 1999; 10, 451-471.

4. Sunilkumar, M.H. Correlation of domination parameters with physicochemical properties of octane isomers. Applied Mathematics and Nonlinear Sciences. 2016; 1, 345-352.

5. Chellali, M.; Haynes, T.W.; Hedetniemi, S.T.; Lewis T.M. On ve-degrees and ev-degrees in graphs, .Discrete Mathematics. 2017; 340, 31-38.

6. Randić, M. Characterization of molecular branching. Journal of the American Chemical Society. 1975; 97, 6609-6615.

7. Kincaid, R.K.; Kunkler, S.J.; Lamar, M.D.; Phillips, D.J. Algorithms and complexity results for findings graphs with extremal Randić index. Networks. 2016; 67, 338-347.

8. Banerjee, A.; Mehatari, R. An eigenvalue localization theorem for stochastic matrices and its application to Randić matrices. Linear Algebra Applications 2016; 505, 85-96.

9. Gu, R.; Huang, F.; Li, X. Skew Randić matrix and skew Randić energy. Transaction on Combinatorics 2016; 5,1-14. 